\title{
PRELIMINARY ANALYSIS OF LED ENHANCED SIGNS AT A PASSIVE RURAL LEVEL CROSSING
}

\author{
Adrian D Hellman \\ Volpe, The National Transportation Systems \\ Center \\ Cambridge, MA USA
}

\author{
Aaron Lamplugh \\ Volpe, The National Transportation Systems \\ Center \\ Cambridge, MA USA
}

\begin{abstract}
The purpose of this research was to measure motor vehicle speed profiles at a rural level crossing following the replacement of the existing Crossbuck signs and Advance Warning signs (AWSs) with flashing light-emitting diode (LED) versions. Measurements were recorded at four discrete locations on the approach to the level crossing, during three distinct phases: baseline, or prior to any changes at the crossing, after the installation of LED enhanced Crossbuck signs, and after the installation of LED AWSs. Test results after the installation of the LED enhanced Crossbuck signs showed: 1) a statistically significant decrease of $2.9 \mathrm{mph}-3.3 \mathrm{mph}$ in mean vehicle speed at night at the four measurement locations and 2) improvements of $1.5 \%-2.5 \%$ in the rate of mean vehicle speed decrease for both daytime and nighttime data sets. The unplanned addition of a double yellow centerline by the local public works department prevented the evaluation of the LEDenhanced AWS technology.
\end{abstract}

\section{INTRODUCTION}

The use of light-emitting diode (LED) technology as a means to enhance the conspicuity of highway regulatory warning signs has been an option in the United States (U.S.) since the publication of the 2003 edition of the Manual on Uniform Traffic Control Devices (MUTCD). The need for such technology stems from the substantial cost of upgrading from a passive to an active warning system, as well as the high relative frequency of incidents that occur at intersections equipped with passive warning devices.

In the past five years, LED enhanced warning devices have been implemented on a limited basis at level crossings throughout the U.S. While studies have been undertaken to evaluate the effects of LED enhanced traffic signs at highway intersections, no studies thus far have been published on their use in level crossing applications [1].

\section{OBJECTIVES}

The purpose of this research was to assess the impact of two LED enhanced passive warning device configurations on the speed profiles of motor vehicles as they approached a rural level crossing. In the first configuration, the standard grade (level) crossing Crossbuck (R15-1) ${ }^{1}$ signs were replaced by LED enhanced Crossbuck signs. In the second configuration, the LED enhanced Crossbuck signs remained in operation and the grade (level) crossing Advance Warning signs (AWSs) (W10-1)1 on the crossing approaches were replaced by LED enhanced versions.

For this study, motor vehicle speed profiles were measured before and after the installation of the LED enhanced signs. The approach used was to first deploy and then measure the impact of the LED Crossbuck signs. Next, the AWSs were installed. Since the Crossbuck signs remained deployed, it was not possible to directly measure the impact of the AWSs on motor vehicle speed. However, it was hypothesized that using the two signs in tandem on each approach would yield a greater reduction in motor vehicle speeds than either sign would individually. Daytime and nighttime data samples were analyzed separately.

\section{SITE SELECTION REQUIREMENTS}

The site requirements for this study are as follows:

- The candidate level crossing is equipped with passive warning devices only.

- The level crossing is not STOP-sign controlled. Since motor vehicles reduce speed to zero at a STOP-sign equipped crossing regardless of the presence of a train, it would be difficult to attribute changes in vehicle speed profiles to LED sign technology.

- The highway intersection in closest proximity to the level crossing has no impact on vehicle speed profiles

\footnotetext{
${ }^{1}$ The Grade Crossing (R15-1) and Advance Warning (W10-1) are defined in the Manual of Uniform Traffic Control Devices 2009 Edition, Chapter 8B, Signs and Markings. http://mutcd.fhwa.dot.gov/htm/2009/part8/part8b.htm.
} 
at the crossing.

- The level crossing is located on a railroad main line with daily train movements.

These requirements limited the total number of candidate level crossings, especially those that could be reached with a one-day roundtrip by automobile from the Volpe Center. This was crucial, since frequent visits to the test site were necessary to download data files and maintain the data collection system.

\section{TEST LOCATION}

The level crossing is shown in Figure 1. It is located in the town of Swanton, Vermont on the Swanton subdivision of the New England Central Railroad. The intersecting roadway, Lakewood Drive, is a two-lane rural local road with a posted speed limit of $30 \mathrm{mph}$. As of 2008, the roadway average annual daily traffic (AADT) was 396 motor vehicles. Approximately three percent of the traffic consisted of commercial vehicles. An aerial view of the level crossing is shown in Figure 2. The crossing is protected by a pair of regulatory Crossbuck signs installed $15 \mathrm{ft}$-20 ft. from either side of the track midpoint. These are complemented by YIELD (R1-2) signs installed on separate posts $50 \mathrm{ft}-90 \mathrm{ft}$. from the crossing. An AWS is installed $238 \mathrm{ft}$. north of the crossing centerline and another is installed $564 \mathrm{ft}$. south of the crossing centerline. There is a highway STOP sign at the intersection with Route 78, $300 \mathrm{ft}$. north of the crossing. Route 78 is the northernmost Lake Champlain highway crossing between Vermont and New York State and serves a significant amount of commercial vehicle traffic.

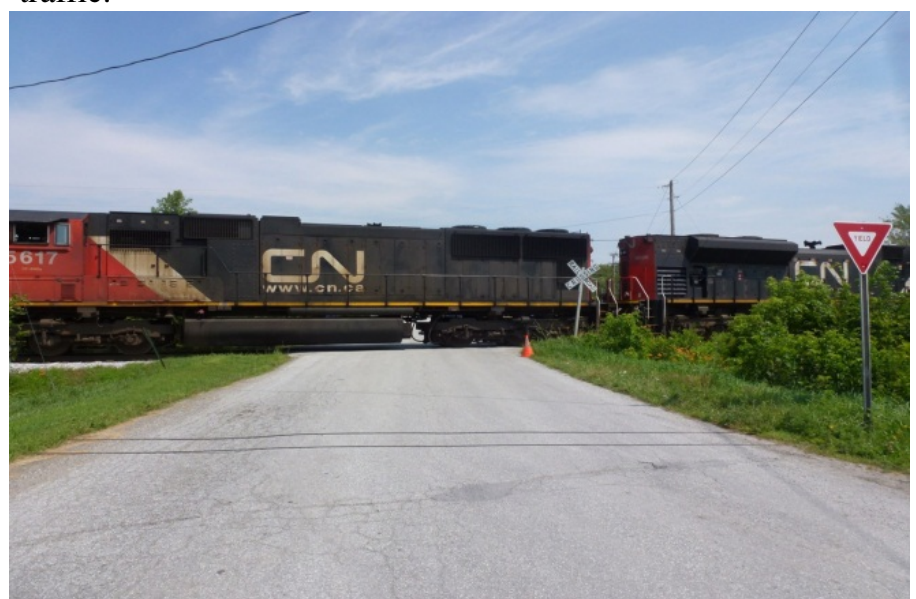

FIGURE 1. THE LAKEWOOD DRIVE LEVEL CROSSING ENVIRONMENT PRIOR TO THE LED SIGN STUDY

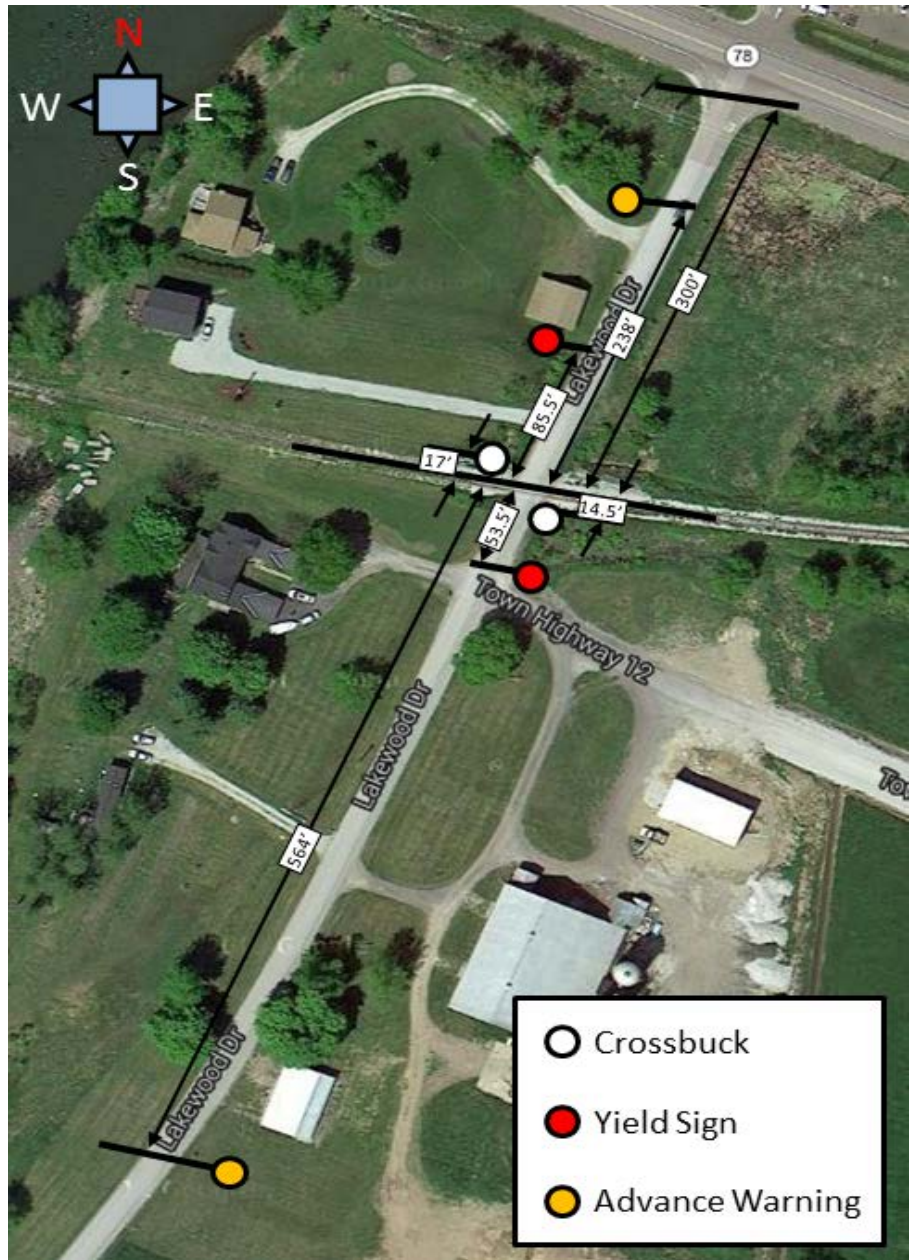

FIGURE 2. DIAGRAM OF THE LAKEWOOD DRIVE LEVEL CROSSING WITH DISTANCES TO THE TRACK CENTERLINE

\section{LED SIGN PROPERTIES}

The signs selected for the study, shown in Figure 3, were TAPCO ${ }^{\circledR}$ BlinkerSigns ${ }^{\circledR}$, purchased from CTC, Inc. The R151 Crossbuck signs measure 48 in. x 9 in., and the W10-1 AWSs each have a diameter of 36 in. The signs satisfy the guidelines in MUTCD section 2A.07 for reflectivity and LED placement, and the LED color matches the background color of the warning sign. The LED lights flash at a frequency of one Hertz $(1 \mathrm{~Hz})$.

The signs are powered by nickel-metal hydride batteries and have solar panels affixed to their poles for charging. The batteries are designed to operate continuously without charging for a minimum of 14 days, and have a lifespan of up to five years. Each LED light consumes one watt of power and is designed with a life expectancy in excess of 100,000 hours [2]. 
The Crossbuck signs are configured with 16 LED lights and the AWSs are equipped with 10 lights.
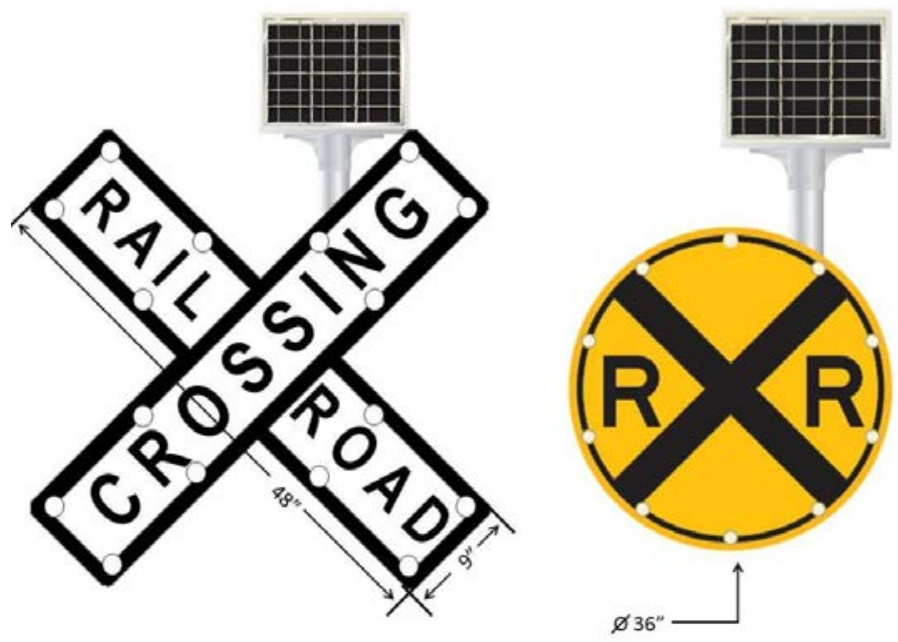

FIGURE 3. A DIAGRAM OF BOTH LED SIGNS WITH DIMENSIONS. (LEFT) LED CROSSBUCK (R15-1). (RIGHT) LED ADVANCE WARNING SIGN (W10-1)

\section{DATA COLLECTION SYSTEM}

The data collection system is a trailer-mounted equipment platform with a $32 \mathrm{ft}$. extendable mast. The device includes the following components:

- A Pan-Tilt-Zoom (PTZ) camera system mounted on top of the mast

- A ruggedized, panel-mounted computer

- A machine vision processing (MVP) system capable of performing video-based vehicle detection, speed measurement, and vehicle classification

- A wireless cellular modem for remote access and control of certain data collection system features

The core of the data collection system is the Autoscope Pro Terra ${ }^{\circledR}$ MVP system, manufactured by Econolite Group, Inc. The system is autonomously powered by a bank of twelve 6volt direct current (VDC) deep-cycle lead-acid batteries that are charged by four adjustable, 115-watt solar panels. The data collection system is shown in Figure 4.

As shown in Figure 5, vehicles approaching the crossing from the south were detected at four locations. These locations corresponded to Autoscope virtual vehicle detectors positioned at distances of $12.5 \mathrm{ft}$., $72.5 \mathrm{ft}$., $137.5 \mathrm{ft}$., and $202.5 \mathrm{ft}$. from the midpoint of the railroad track. Detector 1 was placed beyond the sign legibility distance for the typical driver of $180 \mathrm{ft}$. as

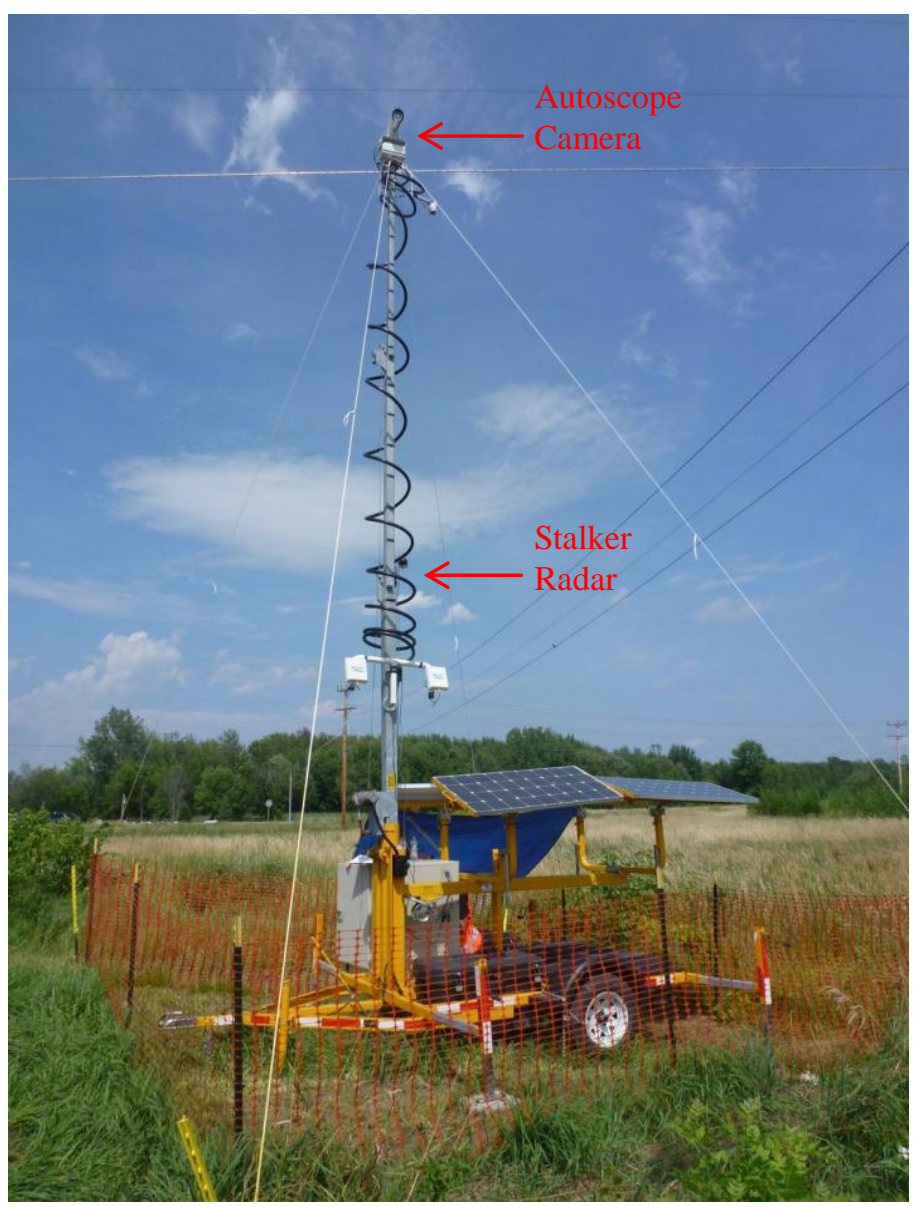

FIGURE 4. THE FRA MOBILE DRIVER FEEDBACK DEVICE DEPLOYED AT THE LAKEWOOD DRIVE LEVEL CROSSING IN SWANTON, VERMONT

expressed in the MUTCD. ${ }^{2}$ Presumably, this would allow for the measurement of vehicle speed before any speed reduction was elicited by the Crossbuck sign. Detectors 2, 3, and 4 recorded the remainder of the vehicle speed profile on the crossing approach.

Vehicle speeds were recorded by a Stalker ${ }^{\circledR}$ radar, which was also mounted to the data collection system mast. The radar was configured to record all vehicles traveling northbound, through the crossing, at speeds in excess of $12 \mathrm{mph}$. The radar was programmed to acquire targets with the strongest reflected signal.

\footnotetext{
${ }^{2}$ Manual of Uniform Traffic Control Devices 2009 Edition, Chapter 2C. Warning Signs and Object Markers,

http://mutcd.fhwa.dot.gov/htm/2009/part8/part8b.htm.
} 


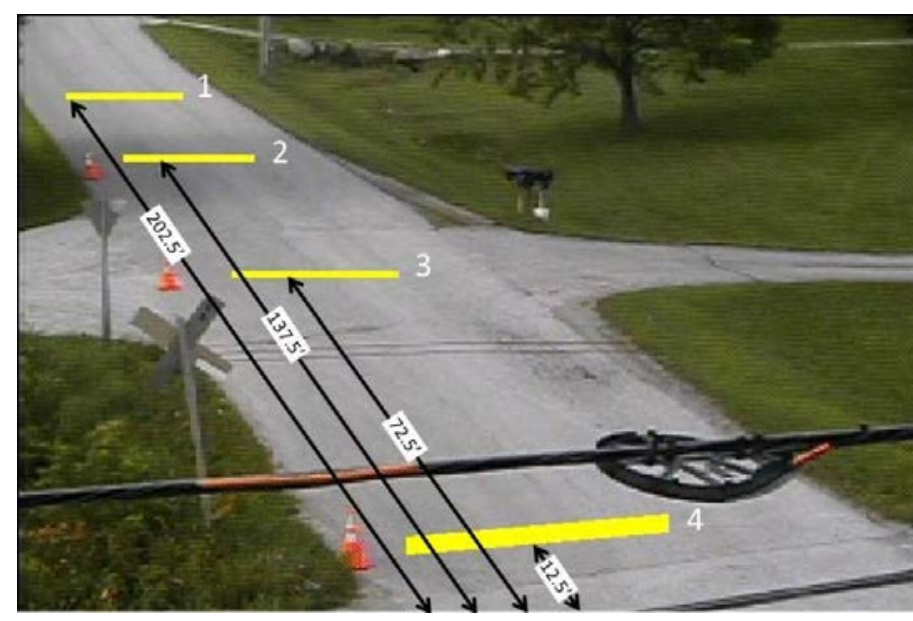

FIGURE 5. THE AUTOSCOPE CONFIGURATION FILE SHOWING DETECTOR PLACEMENT WITH

CORRESPONDING DETECTOR NUMBERS, AND DISTANCES

TO THE CROSSING CENTER-LINE (CROSSING NOT

SHOWN)

\section{DATA COLLECTION SCHEDULE}

As shown in Table 1, the test consisted of three phases; Baseline, Crossbuck, and Crossbuck in tandem with AWS. Each phase was designed to include a four-week novelty period corresponding to the installation of new hardware. Following the novelty period, two weeks of motor vehicle speed profiles were recorded.

On October 1st, 2013, a double solid yellow centerline was painted on the center of Lakewood Drive by the local highway department. As seen in Table 1, this occurred during the middle of the Phase 2 (Crossbuck) data collection. A follow-up analysis of the Phase 2 data showed significant differences in mean vehicle speeds before and after the addition of the

TABLE 1. PROJECT PHASE SCHEDULE

\begin{tabular}{|c|c|c|c|}
\hline \multicolumn{4}{|l|}{ Phase 1 (Baseline) } \\
\hline & Start Date & End Date & Total Days \\
\hline Novelty Period & $6 / 24 / 2013$ & $7 / 26 / 2013$ & 33 \\
\hline Data Collection & $7 / 27 / 2013$ & $8 / 28 / 2013$ & 33 \\
\hline \multicolumn{4}{|c|}{ Phase 2 (Crossbuck) } \\
\hline & Start Date & End Date & Total Days \\
\hline Novelty Period & $8 / 29 / 2013$ & $9 / 25 / 2013$ & 28 \\
\hline Data Collection & 9/26/2013 & $10 / 8 / 2013$ & 13 \\
\hline \multicolumn{4}{|c|}{ Phase 3 (Crossbuck and AWS) } \\
\hline & Start Date & End Date & Total Days* \\
\hline Novelty Period & $10 / 9 / 2013$ & $10 / 15 / 2013$ & 7 \\
\hline Data Collection & $10 / 16 / 2013$ & $10 / 28 / 2013$ & 13 \\
\hline
\end{tabular}

*Novelty period less than 4 weeks centerline. This marked a significant change in the test environment from the Phase 1 baseline conditions and precluded the use of Phase 3 (AWS) data in formulating any substantial conclusions related to the tandem sign configuration. For the remainder of this paper, the Phase 2 data collected before and after the addition of the centerline will be known as Phases 2A and 2B, respectively. The Phase 2A and 2B schedules are shown in Table 2.

\section{TABLE 2. PHASE 2 REVISED SCHEDULE}

\begin{tabular}{l|ccc}
\hline Phase Name & Start Date & End Date & Number of Days \\
Phase 2A & $09 / 26 / 2013$ & $09 / 30 / 2013$ & 5 \\
Phase 2B & $10 / 02 / 2013$ & $10 / 08 / 2013$ & 7 \\
\hline
\end{tabular}

\section{DATA ANALYSIS}

The data analyzed in this study consisted of mean vehicle speed profiles that were not affected by weather, lighting, or traffic conditions. Tables 3 and 4 show vehicle speed profiles following the activation of the LED enhanced Crossbuck sign. During daytime conditions, found in Table 3, none of the detectors exhibited statistically significant changes in mean vehicle speed. Referring to Table 4, all detectors experienced a decrease in nighttime mean vehicle speed between Phases 1 and 2A, ranging from $2.89 \mathrm{mph}$ at detector 4 to $3.32 \mathrm{mph}$ at detector 3. The results, presented were statistically significant at the 95\% confidence level. At this level of confidence it is highly probable that the LED enhanced Crossbuck signs were responsible for the reductions in mean vehicle speeds.

TABLE 3. PHASE 1 ( $\mathrm{N}=1486)$ AND PHASE 2A $(\mathrm{N}=527)$ COMPARISON - DAYTIME

\begin{tabular}{lccccc}
\hline $\begin{array}{l}\text { Detector } \\
\text { Name }\end{array}$ & $\begin{array}{c}\text { Distance from } \\
\text { Crossing (feet) }\end{array}$ & $\begin{array}{c}\overline{\boldsymbol{x}}_{1} \\
(\mathrm{mph})\end{array}$ & $\begin{array}{c}\overline{\boldsymbol{x}}_{2, \boldsymbol{A}} \\
(\mathrm{mph})\end{array}$ & $\begin{array}{c}\overline{\boldsymbol{x}}_{1}-\overline{\boldsymbol{x}}_{2, \boldsymbol{A}} \\
(\mathrm{mph})\end{array}$ & $\begin{array}{c}p \text {-value } \\
<0.005^{*}\end{array}$ \\
Detector 1 & 202.5 & 31.45 & 31.92 & -0.47 & $\mathrm{~N}$ \\
Detector 2 & 137.5 & 28.45 & 28.87 & -0.42 & $\mathrm{~N}$ \\
Detector 3 & 72.5 & 25.42 & 25.32 & 0.10 & $\mathrm{~N}$ \\
Detector 4 & 12.5 & 23.05 & 22.64 & 0.41 & $\mathrm{~N}$ \\
\hline
\end{tabular}

*Significant at 95\% Confidence Level

TABLE 4. PHASE $1(\mathrm{~N}=282)$ AND PHASE $2 \mathrm{~A}(\mathrm{~N}=132)$ COMPARISON - NIGHTTIME

\begin{tabular}{lccccc}
\hline Detector & $\begin{array}{c}\text { Distance from } \\
\text { Crossing (feet) }\end{array}$ & $\begin{array}{c}\overline{\boldsymbol{x}}_{1} \\
(\mathrm{mph})\end{array}$ & $\begin{array}{c}\overline{\boldsymbol{x}}_{2, \boldsymbol{A}} \\
(\mathrm{mph})\end{array}$ & $\begin{array}{c}\overline{\boldsymbol{x}}_{1}-\overline{\boldsymbol{x}}_{2, \boldsymbol{A}} \\
(\mathrm{mph})\end{array}$ & $\begin{array}{c}p \text {-value } \\
<0.005^{*}\end{array}$ \\
Detector 1 & 202.5 & 32.97 & 30.02 & 2.95 & $\mathrm{Y}$ \\
Detector 2 & 137.5 & 30.55 & 27.46 & 3.09 & $\mathrm{Y}$ \\
Detector 3 & 72.5 & 27.56 & 24.24 & 3.32 & $\mathrm{Y}$ \\
Detector 4 & 12.5 & & 22.03 & 2.89 & $\mathrm{Y}$ \\
\hline
\end{tabular}

*Significant at 95\% Confidence Level

Tables 5 and 6 illustrate the change in mean vehicle speeds after the addition of the centerline. As shown in Tables 5 and 6, 
a significant decrease in speed occurred at three detectors during the daytime, while a significant increase in speed occurred at three detectors during the nighttime. This seems to indicate that the addition of the centerline had varying, but substantial effects on mean vehicle speeds.

TABLE 5. PHASE 2A ( $\mathrm{N}=527)$ AND PHASE 2B $(\mathrm{N}=789)$ COMPARISON - DAYTIME

\begin{tabular}{|c|c|c|c|c|c|}
\hline $\begin{array}{l}\text { Detector } \\
\text { Name }\end{array}$ & $\begin{array}{l}\text { Distance from } \\
\text { Crossing (feet) }\end{array}$ & $\begin{array}{l}\bar{x}_{z, A} \\
(\mathrm{mph})\end{array}$ & $\begin{array}{l}\overline{\boldsymbol{x}}_{2,} \\
(\mathrm{mph})\end{array}$ & $\begin{array}{c}\bar{x}_{z, A}-\bar{x}_{z \Omega} \\
(\mathrm{mph})\end{array}$ & $\begin{array}{l}p \text {-value } \\
<0.005^{*}\end{array}$ \\
\hline Detector 1 & 202.5 & 31.92 & 30.71 & 1.21 & $\mathrm{Y}$ \\
\hline Detector 2 & 137.5 & 28.87 & 27.64 & 1.23 & $\mathrm{Y}$ \\
\hline Detector 3 & 72.5 & 25.32 & 24.56 & 0.76 & $\mathrm{Y}$ \\
\hline Detector 4 & 12.5 & 22.64 & 22.43 & 0.21 & $\mathrm{~N}$ \\
\hline
\end{tabular}

*Significant at $95 \%$ Confidence Level

TABLE 6. PHASE 2A ( $\mathrm{N}=132)$ AND PHASE $2 \mathrm{~B}(\mathrm{~N}=128)$ COMPARISON - NIGHTTIME

\begin{tabular}{lccccc}
\hline $\begin{array}{l}\text { Detector } \\
\text { Name }\end{array}$ & $\begin{array}{c}\text { Distance from } \\
\text { Crossing (feet) }\end{array}$ & $\begin{array}{c}\overline{\boldsymbol{x}}_{\mathbf{2} \boldsymbol{A}} \\
(\mathrm{mph})\end{array}$ & $\begin{array}{c}\overline{\boldsymbol{x}}_{\mathbf{2 g}} \\
(\mathrm{mph})\end{array}$ & $\begin{array}{c}\overline{\boldsymbol{x}}_{\mathbf{2} \boldsymbol{A}}-\overline{\boldsymbol{x}}_{\mathbf{2 g}} \\
(\mathrm{mph})\end{array}$ & $\begin{array}{c}\text { p-value } \\
<0.005^{*}\end{array}$ \\
Detector 1 & 202.5 & 30.02 & 31.97 & -1.95 & $\mathrm{~N}$ \\
Detector 2 & 137.5 & 27.46 & 29.38 & -1.92 & $\mathrm{Y}$ \\
Detector 3 & 72.5 & 24.24 & 26.62 & -2.37 & $\mathrm{Y}$ \\
Detector 4 & 12.5 & 22.03 & 24.79 & -2.76 & $\mathrm{Y}$ \\
\hline
\end{tabular}

*Significant at 95\% Confidence Level

The addition of the centerline on October 1st precluded the comparison of the tandem LED system with the LED-enhanced Crossbuck sign. Therefore, a significance test was not used to compare Phases 2B and 3. However, the mean vehicle speeds for all four detectors did display a general increase during both daytime and nighttime. Some possible explanations for this trend are:

- The novelty effect from the LED enhanced Crossbuck sign at night diminished

- The motorist population adjusted to narrower road lane width

- The addition of the LED AWSs led to increased visibility of highway centerline and lanes

While any or all of these explanations may be valid, the fact that they occurred concurrently prevented any characterization of the impact of the LED sign tandem design.

Figure 6 shows the daytime mean vehicle speed at each detector as a percentage of the mean vehicle speed at Detector 1. The plots show that Phase 2A exhibited a greater decrease in speed at Detector 3 (1\%) and Detector 4 (2.5\%) as compared to Phase 1. This suggests that the LED enhanced Crossbuck signs had an effect on vehicle speeds within $100 \mathrm{ft}$. of the crossing.
Figure 7 shows the nighttime mean vehicle speed at each detector as a percentage of the mean vehicle speed at Detector 1. The plots show that Phase 2A exhibited a greater decrease in speed than Phase 1 at Detector 2 (1.2\%), Detector 3 (2.85\%), and Detector 4 (2.25\%). The data shows that the impact of the LED enhanced Crossbuck signs was greater at night than during the day.

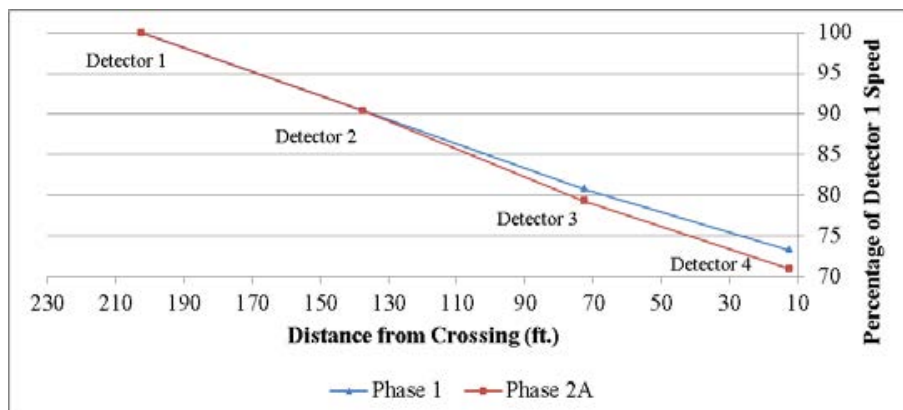

FIGURE 6. RATE OF MEAN SPEED DECREASE OVER THE DETECTION ZONE AS A PERCENTAGE OF THE DETECTOR 1 MEAN SPEED FOR DAYTIME DATA

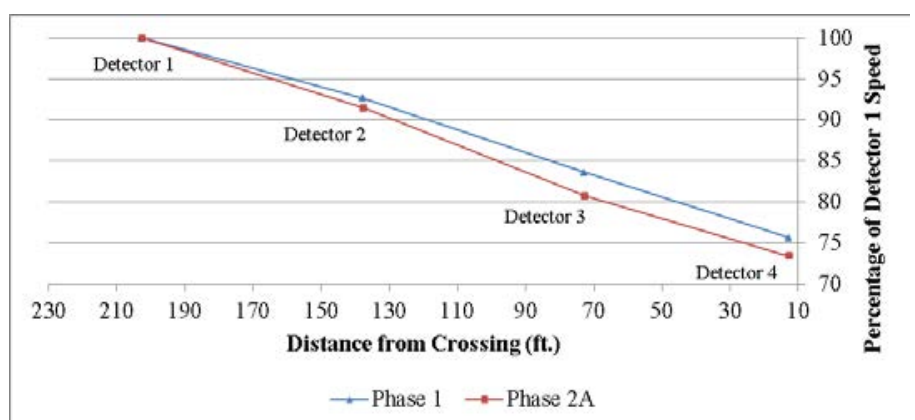

FIGURE 7. RATE OF MEAN SPEED DECREASE OVER THE DETECTION ZONE AS A PERCENTAGE OF THE DETECTOR 1 MEAN SPEED FOR NIGHTTIME DATA

Prior to the discovery of the addition of the centerline, it was posited that seasonal variation in the vehicle composition during the course of the analysis was partially responsible for the counterintuitive daytime results observed in Phases 2 and 3. This theory was considered especially plausible since Lakewood Drive serves a large number of boating enthusiasts who tow their vessels to a nearby boat launch during the June to September timeframe. A decrease in this group may have occurred as the summer concluded, causing the composition of the vehicle classes, and the resulting mean vehicle speeds, to fluctuate. Given the effect of the centerline on the Phase 2B and Phase 3 results, only the vehicle compositions of Phase 1 and 2A were compared. For each phase, a 3-day sample of daytime data from one Saturday, one Sunday, and one Monday 
was selected. The Phase 1 and 2A samples consisted of 701 and 501 vehicles, respectively. The vehicle class designations are shown in Table 7.

As shown in Table 8, Class A vehicles represented the vast majority of all vehicles traversing Lakewood Drive during the daytime in Phases 1 and 2A. Class B was the only other vehicle class to comprise more than about $1 \%$ of the total sample population. Vehicle classes $\mathrm{C}$ through $\mathrm{H}$ represented less than $3 \%$ of the sample population, when combined.

TABLE 7. VEHICLE CLASS DESIGNATIONS

\begin{tabular}{|l|l|}
\hline Class & Description \\
\hline A- Light Vehicle & $\begin{array}{l}\text { Pick-up trucks, SUVs, Autos, Vans, and } \\
\text { Minivans }\end{array}$ \\
\hline $\begin{array}{l}\text { B - Light Vehicle with } \\
\text { Trailer }\end{array}$ & Any Class A vehicle with a trailer in tow \\
\hline $\begin{array}{l}\text { C - Commercial } \\
\text { Vehicle }\end{array}$ & $\begin{array}{l}\text { Semi-Truck, Delivery truck, and moving } \\
\text { vans/trucks }\end{array}$ \\
\hline $\begin{array}{l}\text { D - Commercial } \\
\text { Vehicle with Trailer }\end{array}$ & Any Class C vehicle with a trailer in tow \\
\hline E- Bus & Public and private buses \\
\hline $\begin{array}{l}\text { F - Recreational } \\
\text { Vehicles }\end{array}$ & $\begin{array}{l}\text { Motor vehicles intended for leisure activity } \\
\text { (does not include trailers) }\end{array}$ \\
\hline G-Motorcycles & 2-wheeled motorized vehicles \\
\hline H - Other & $\begin{array}{l}\text { Any vehicle not included in the previous class } \\
\text { descriptions }\end{array}$ \\
\hline
\end{tabular}

TABLE 8. PERCENTAGE OF SAMPLE POPULATION BY VEHICLE CLASS

\begin{tabular}{|c|c|c|c|c|c|c|c|c|}
\hline Class & $\begin{array}{c}\mathrm{A} \\
(\%)\end{array}$ & $\begin{array}{c}\mathrm{B} \\
(\%)\end{array}$ & $\begin{array}{c}\mathrm{C} \\
(\%)\end{array}$ & $\begin{array}{c}\mathrm{D} \\
(\%)\end{array}$ & $\begin{array}{c}\mathrm{E} \\
(\%)\end{array}$ & $\begin{array}{c}\mathrm{F} \\
(\%)\end{array}$ & $\begin{array}{c}\mathrm{G} \\
(\%)\end{array}$ & $\begin{array}{c}\mathrm{H} \\
(\%)\end{array}$ \\
\hline $\begin{array}{c}\text { Phase 1 } \\
(\mathrm{n}=701)\end{array}$ & 90.73 & 6.42 & 0.57 & 0.57 & 0.29 & 0.14 & 1.14 & 0.14 \\
\hline $\begin{array}{c}\text { Phase 2A } \\
(\mathrm{n}=501)\end{array}$ & 89.22 & 8.38 & 0.80 & 0.60 & 0.00 & 0.00 & 0.80 & 0.20 \\
\hline
\end{tabular}

\section{DISCUSSION}

When the centerline was added to Lakewood Drive on October 1st, a statistically significant change in mean vehicle speeds was observed. This effect is believed to have been caused primarily by the addition of the centerline. This theory is supported by the findings of other researchers who have investigated the impact of pavement markings on vehicle speeds. One such study, conducted in Connecticut, found that the addition of a highway edgeline marking led vehicle speeds to increase at nighttime and decrease during the daytime [3]. Another report, which contained a meta-analysis of 14 centerline pavement marking studies, showed that the addition of a centerline to a previously unmarked roadway had an effect on speeds ranging from to $-1.2 \mathrm{mph}$ to $+5.6 \mathrm{mph}$ with an average change of $+1.9 \mathrm{mph}$ [4]. The meta-analysis did not distinguish between daytime and nighttime measurements.
Based on this evidence, the vehicle speed fluctuations observed on Lakewood Drive appear reasonable.

There is little likelihood that the abrupt increase in nighttime mean vehicle speeds after the double yellow centerline was added occurred at random rather than as a result of the addition of the centerline. The decreases in the daytime mean vehicle speeds after the centerline was introduced, probably occurred as a result of the decrease in lane width [5].

\section{CONCLUSIONS}

The objective of this research was to measure the impact of a phased introduction of LED sign technology on motor vehicle speed profiles. The experimental approach was to compare the Phase 1 baseline data with the Phase 2 LED Crossbuck data and the Phase 3 tandem LED Crossbuck/AWS configuration. Under ideal conditions, any statistically significant change in a dependent variable (motor vehicle speed profiles) would correlate to fluctuations in a single independent variable (the LED signs). In most controlled field tests, a small amount of experimental error and bias will occur due to the presence of uncontrollable variables. The effect of these variables should be mitigated so that the study results accurately reflect the impact of the independent variable. The addition of the centerline on Lakewood Drive introduced an experimental error into the test environment that weakened the correlation between motor vehicle speed profiles and the presence of the LED signs.

Because the test environment was altered, only data collected prior to the introduction of the centerline was considered reliable and, as a result, conclusions were limited. For instance, the added effect of the LED enhanced AWSs could not be measured due to the addition of a second independent variable (the centerline) at the time of data collection. It was possible, however, to formulate conclusions about the LED Crossbuck sign based on useable data from Phase 2A.

The comparison of Phase 1 and Phase 2A mean vehicle speeds showed a statistically significant decrease of $2.9 \mathrm{mph}-$ $3.3 \mathrm{mph}$ at night as a result of the installation of the LEDenhanced Crossbuck sign. The decreases were statistically significant at all vehicle detectors. No statistically significant increase or decrease in mean vehicle speeds was observed during the day.

While the results of the Phase 1-Phase 2A comparison appeared promising, the addition of the centerline prevented the measurement of any long-term trends attributed to the LEDenhanced AWS technology. Also, the centerline treatment prevented the comparison of the tandem LED sign configuration from Phase 3 with the baseline configuration. 


\section{ACKNOWLEDGMENTS}

The U.S. Department of Transportation (U.S. DOT) Federal Railroad Administration (FRA) Office of Research and Development sponsored the work leading to this report. The authors would like to thank Sam Alibrahim, Chief of the Office of Research and Development's Train Control and Communications Division, FRA, and Tarek Omar, D.Sc. Program Manager, Train Control and Communications Division, FRA, for their guidance during the project. The authors would also like to thank Frank Frey, Office of Railroad Safety, Highway-Rail Crossing and Trespasser Programs Division, FRA.

\section{REFERENCES}

[1] Gates, T.J., Carlson, P.J. and Hawkins, H.G., 2004, "Field Evaluations of Warning and Regulatory Signs with Enhanced Conspicuity Properties,” Transportation Research Record: Journal of the Transportation Research Board, No. 1862, TRB, National Research Council, Washington, D.C., pp. 64-76.

[2] "E*Signs for Railroad Applications," n.d., Campbell Technology Corporation

[3] “Night Guide - A Side of Pavement Line,” 1955, Engineering News Record, Vol. 154, No. 14, p. 45.

[4] Davidse, R., van Driel, C., and Goldenbeld, C., 2004, “The Effect of Altered Road Markings on Speed and Lateral Position,” SWOV Institute for Road Safety Research, The Netherlands.

[5] Stein, W.J. and Neuman, T.R., 2007, "Mitigation Strategies for Design Exceptions,” Washington, DC: U.S. Department of Transportation, Federal Highway Administration. 